\title{
Airflow limitation in people living with HIV and matched uninfected controls
}

\author{
Andreas Ronit, ${ }_{1}^{1}$ Jens Lundgren, ${ }^{2}$ Shoaib Afzal, ${ }^{3}$ Thomas Benfield ${ }_{1}^{4}$ Ashley Roen, ${ }^{5}$ \\ Amanda Mocroft, ${ }^{5}$ Jan Gerstoft, ${ }^{1}$ Børge G Nordestgaard, ${ }^{3,6}$ Jørgen Vestbo, ${ }^{7}$ \\ Susanne D Nielsen, ${ }^{1}$ on behalf of the Copenhagen Co-morbidity in HIV infection \\ (COCOMO) study group
}

\begin{abstract}
- Additional material is published online only. To view please visit the journal online (http://dx.doi.org/10.1136/ thoraxjnl-2017-211079).
\end{abstract}

'Viro-immunology Research Unit, Department of Infectious Diseases, Rigshospitalet, University of Copenhagen Copenhagen, Denmark ${ }^{2}$ CHIP, Department of Infectious Diseases, Rigshospitalet, University of Copenhagen Copenhagen, Denmark ${ }^{3}$ The Copenhagen General Population Study, Herlev and Gentofte Hospital, Copenhagen University Hospital, Herlev, Denmark

${ }^{4}$ Department of Infectious Diseases, Hvidovre Hospital, University of Copenhagen, Hvidovre, Denmark

${ }^{5}$ Centre for Clinical Research, Epidemiology, Modelling and Evaluation (CREME), Institute for Global Health, UCL, London, UK

${ }^{6}$ Faculty of Health and Medical Sciences, Copenhagen University Hospital, Copenhagen, Denmark ${ }^{7}$ Division of Infection, Immunity and Respiratory Medicine, University of Manchester, Manchester, UK

\section{Correspondence to}

Dr Susanne D Nielsen, Viroimmunology Research Unit, Department of Infectious Diseases, Copenhagen University Hospital, Copenhagen 2200, Denmark: sdn@dadlnet.dk

Received 24 September 2017 Revised 13 December 2017 Accepted 22 December 2017 Published Online First 13 January 2018

Check for updates

To cite: Ronit A, Lundgren J, Afzal $S$, et al. Thorax

2018:73:431-438.

\begin{abstract}
Introduction Whether HIV influences pulmonary

function remains controversial. We assessed dynamic pulmonary function in people living with HIV (PLWHIV) and uninfected controls.

Methods A total of 1098 PLWHIV from the Copenhagen Co-morbidity in HIV infection study and 12161 age-matched and sex-matched controls from the Copenhagen General Population Study were included. Lung function was assessed using FEV, and FVC, while airflow limitation was defined by the lower limit of normal (LLN) of FEV, FVC and by FEV, I $\mathrm{FVC}<0.7$ with $\mathrm{FEV}$, predicted $<80 \%$ (fixed). Logistic and linear regression models were used to determine the association between HIV and pulmonary function adjusting for potential confounders (including smoking and socioeconomic status).
\end{abstract}

Results In predominantly white men with mean (SD) age of $50.6(11.1)$ the prevalence of airflow limitation (LLN) was $10.6 \%$ (95\% Cl $8.9 \%$ to $12.6 \%$ ) in PLWHIV and $10.6 \%(95 \% \mathrm{Cl} 10.0$ to 11.1$)$ in uninfected controls. The multivariable adjusted OR for airflow limitation defined by LLN for HIV was $0.97(0.77-1.21, \mathrm{P}<0.78)$ and $1.71(1.34-2.16, P<0.0001)$ when defined by the fixed criteria. We found no evidence of interaction between HIV and cumulative smoking in these models (P interaction: 0.25 and 0.17 for LLN and fixed criteria, respectively). HIV was independently associated with $197 \mathrm{~mL}(152-242, \mathrm{P}<0.0001)$ lower FEV and $395 \mathrm{~mL}$ (344-447, $P<0.0001)$ lower FVC, and 100 cells $/ \mathrm{mm}^{3}$ lower CD4 nadir was associated with $30 \mathrm{~mL}(7-52$, $\mathrm{P}<0.01)$ lower $F E V$, and $51 \mathrm{~mL}(24-78, \mathrm{P}<0.001)$ lower FVC.

Conclusion HIV is a risk factor for concurrently decreased FEV, and FVC. This excess risk is not explained by smoking or socioeconomic status and may be mediated by prior immunodeficiency.

Trial registration number NCT02382822.

\section{INTRODUCTION}

Morbidity and mortality due to non-AIDS comorbidity have become a major focus in clinical care of people living with HIV (PLWHIV). Cardiovascular disease, bone, metabolic and renal diseases have received much attention, and specific recommendations for prevention are available for these conditions. ${ }^{1}$ COPD is a world-leading cause of life years lost in the general population, ${ }^{2}$ and is associated

\section{Key messages}

What is the key question?

- Is pulmonary function lower in people with HIV compared with epidemiologically well-matched uninfected controls?

What is the bottom line?

- HIV is independently associated with lower FEV and FVC after adjustment for early-life and late-life risk factors.

Why read on?

- This study represents the largest HIV spirometry study and provides detailed information on respiratory risk factors and self-reported morbidity.

with modifiable risk factors. ${ }^{3}$ Despite this, COPD has received less attention in clinical management of PLWHIV.

The prevalence of COPD in PLWHIV is likely high with estimates from the combination antiretroviral therapy (cART) era exceeding 15\% (summarised in online supplementary figure S1). ${ }^{4-9}$ This may be reflected by the increased utilisation of tobacco smoking among PLWHIV, but HIV-associated drivers, such as chronic inflammation and immune activation, may also contribute to the high burden of COPD..$^{10}$ Few studies have used spirometry and included non-HIV controls making it difficult to assess the independent effect of HIV on pulmonary function. ${ }^{471112}$ In addition, most studies have been small and have not appropriately adjusted for confounders. Some smaller studies using non-conventional pulmonary function tests and CT have found evidence that HIV is a risk factor for airway and alveolar abnormalities. ${ }^{13} 14$

In this cross-sectional study we evaluate the prevalence of airflow limitation and associated risk factors in a large cohort of PLWHIV from the Copenhagen Co-morbidity in HIV infection (COCOMO) study and matched uninfected controls from the Copenhagen General Population Study (CGPS). ${ }^{15}$ Uniform data collection in these cohorts and detailed information on risk factors enabled us to more accurately explore the association between HIV and pulmonary function. 


\section{METHODS}

\section{Study design, study subjects and ethics}

The COCOMO study has been described elsewhere. ${ }^{15}$ In brief, the COCOMO study (NCT02382822) is a prospective study evaluating prevalence, incidence and pathogenesis of non-AIDS comorbidity in PLWHIV in Copenhagen, Denmark. Data collection for PLWHIV was performed at the Department of Infectious Diseases, Rigshospitalet, Copenhagen, and the Department of Infectious Diseases, Hvidovre Hospital, Copenhagen, between March 2015 and November 2016, and includes >40\% of PLWHIV in the capital region of Copenhagen. Matched uninfected controls were recruited between January 2013 and December 2016 at Herlev Hospital, Copenhagen. Controls were not HIV tested but the expected prevalence of HIV among the general population in Denmark is small $(\sim 0.1 \%)$. The CGPS was initiated in 2003 and follows $>100000$ volunteers from the greater Copenhagen area. Of all inhabitants in this area, 25\% of the $20-40$ years old and $100 \%$ of the $>40$ years old were invited.

\section{Spirometry}

The procedure and calibration of spirometry have previously been described. ${ }^{15}$ Briefly, an EasyOne ultrasonic spirometer (ndd Medical, Zürich, Switzerland) was used in accordance with American Thoracic Society/European Respiratory Society guidelines. Predicted values, z-scores and lower limit of normal (LLN) were calculated for prebronchodilator volumes using multiethnic prediction equations and $\mathrm{R}$ macros provided by the Global Lung Function Initiative. ${ }^{16}$ Instructions for spirometry were graded by the examiner as 'easy', 'difficult' or 'very difficult' which was used for sensitivity analysis.

\section{Data collection}

Detailed information related to respiratory health was obtained through self-report using identical questionnaires in both cohorts and included tobacco smoking history, environmental tobacco smoke exposure, educational status and information about early-life and late-life events. Self-reported respiratory morbidity included questions about breathlessness (ie, modified British Medical Research Council (mMRC), cough (for the past 2 months), sputum production (over 3 months within a year) and wheezing (intermittently)). Self-reported COPD, self-reported asthma and use of inhaled medications were recorded as well. HIV-related variables were obtained from patient records. Biochemical analyses were measured uniformly in all participants using standardised hospital assays at Herlev Hospital, Copenhagen. ${ }^{17}$

\section{Study endpoints and selection of covariates}

The primary endpoint of the study was airflow limitation defined according to the LLN, that is, the fifth percentile of the reference population (equivalent to $-1.64 \mathrm{z}$-scores). ${ }^{16}$ As secondary endpoint we assessed $\mathrm{FEV}_{1} / \mathrm{FVC}<0.7$ defined according to the Global Initiative for Chronic Obstructive Lung Disease (GOLD) with $\mathrm{FEV}_{1}$ predicted below $80 \%$ (grade 2 or higher $\mathrm{COPD}^{3}$ ) which has previously been used in the general population and in PLWHIV. ${ }^{18} 19$ Severity of airflow limitation was also graded according to GOLD: $\geq 80$ (mild), 50-79 (moderate), 30-49 (severe), $<30 \% \mathrm{FEV}_{1}$ predicted (very severe). ${ }^{3}$ We also assessed absolute $\mathrm{FEV}_{1}$ and $\mathrm{FVC}$ and their z-scores. A priori selection of confounders was based on clinical assumptions about the relationship between HIV and airflow limitation using directed acyclic graphs.

\section{Statistical analysis}

Uninfected controls were frequency matched with PLWHIV by gender and five age year strata. We randomly identified 14 unique controls for every person with HIV in each age and sex stratum. For men aged 30-35 it was only possible to identify three controls in each 5-year age interval, due to differences in the age and sex distribution between the HIV and the source population for the controls (CGPS) (online supplementary figure S2). Differences in clinical characteristics and spirometry outcomes between those with HIV and matched controls were assessed using t-tests and Mann-Whitney comparisons for continuous data, and $\mathrm{X}^{2}$ tests were used for categorical data. For pulmonary function analyses we omitted tests with $\mathrm{FEV}_{1}$ and FVC below 500 and $400 \mathrm{~mL}$, respectively. 95\% binomial CIs were computed for the prevalence of airflow limitation among PLWHIV and uninfected controls using the Wilson method. Logistic regression analyses were performed to determine risk factors associated with airflow limitation (LLN and $\mathrm{FEV}_{1} /$ FVC $<0.7$ with $\mathrm{FEV}_{1}$ predicted $<80 \%$ ). Univariable and multivariable ORs with $95 \%$ CIs were computed for these analyses. The association between HIV status and $\mathrm{FEV}_{1}$ and FVC as continuous outcomes was assessed using linear regression. For all analyses, we considered a simple demographic model 1 (adjusted for age, sex, ancestry, pack-years of smoking) and model 2 (which included additional confounders, ie, preterm delivery, ${ }^{20}$ passive smoking exposure during childhood, ${ }^{21}$ educational status ${ }^{22}$ and previous pneumonia ${ }^{23}$ ). An interaction term between HIV and pack-years was included to determine whether HIV modifies the effect of smoking on airflow limitation. Self-reported symptoms were compared between those with HIV and matched controls and stratified by smoking status.

Missing values were rare (smoking status was missing for $1.7 \%)$ and analyses were based on a complete case scenario. A few variables (ie, educational status, self-reported COPD, e-cigarette use and marijuana use, and passive smoking during childhood) were not introduced during the first half of recruitment $(n=5658)$ for the CGPS, which reduced the $\mathrm{df}$ for model 2 compared with model 1 , in which all covariates were available.

As a subanalysis, we analysed PLWHIV separately to determine whether HIV-associated variables are associated with spirometric indices (current and nadir CD4+ T cell count, viral load, time living with HIV, previous AIDS defining condition and prior Pneumocystis jirovecii pneumonia (PCP)). As a sensitivity analysis, we repeated logistic and linear regression analyses confining our primary analyses to spirometry measurements that were graded as easy by the examiner. A P value $<0.05$ was used to infer statistical significance. Statistical analyses were performed using R software V.3.3.2 (R Foundation for Statistical Computing, Vienna, Austria).

\section{RESULTS}

\section{Patients}

A total of 1098 PLWHIV and 12161 uninfected controls performed spirometry. We excluded 15 (1.3\%) PLWHIV and $87(0.7 \%)$ uninfected controls from our final analyses due to $\mathrm{FEV}_{1}$ and FVC values below 400 and $500 \mathrm{~mL}$, respectively. Clinical characteristics are depicted in tables 1 and 2. Most PLWHIV were Scandinavian men with mean (SD) age of 50.6 (11.3). There was a larger proportion of current smokers and more cumulative tobacco smoking in PLWHIV. The majority of PLWHIV were receiving cART treatment with suppression of viral replication (table 2). 
Table 1 Clinical characteristics and risk factors for airflow limitation in PLWHIV and uninfected controls

\begin{tabular}{|c|c|c|c|}
\hline & PLWHIV ( $n=1083)$ & Controls $(n=12074)$ & $P$ value \\
\hline \multicolumn{4}{|l|}{ Characteristics } \\
\hline Age, mean (SD) & $50.6(11.3)$ & $52.8(11.5)$ & $<0.0001$ \\
\hline Sex (male), n (\%) & $928(85.7)$ & 9857 (81.6) & 0.001 \\
\hline \multicolumn{4}{|l|}{ Ancestry } \\
\hline Scandinavia, n (\%) & $782(73.3)$ & $10686(89.4)$ & $<0.0001$ \\
\hline Other European, n (\%) & $129(121)$ & $811(6.8)$ & \\
\hline Middle East and Indian subcontinent, n (\%) & $18(1.7)$ & $368(3.1)$ & \\
\hline Other, $\mathrm{n}(\%)$ & $138(12.9)$ & $87(0.7)$ & \\
\hline BMI $\left(\mathrm{kg} / \mathrm{m}^{2}\right)$, mean (SD) & $25.0(4.0)$ & $26.5(4.1)$ & $<0.0001$ \\
\hline \multicolumn{4}{|l|}{ Tobacco exposure } \\
\hline \multicolumn{4}{|l|}{ Smoking status } \\
\hline Current, $\mathrm{n}(\%)$ & $316(29.2)$ & $1556(12.9)$ & $<0.0001$ \\
\hline Former, $\mathrm{n}(\%)$ & $370(34.2)$ & $4602(38.1)$ & \\
\hline Never, n (\%) & $361(33.3)$ & $5726(47.4)$ & \\
\hline Pack-years ${ }^{*}$, median (IQR) & $18.8(6.6-31.1)$ & $15.0(6.0-27.0)$ & $<0.0001$ \\
\hline Any marijuana use ever, n (\%) & $309(30.1)$ & $1105(17.4)$ & $<0.0001$ \\
\hline Current e-cigarette with nicotine use, $n(\%)$ & $38(3.9)$ & $156(2.5)$ & $<0.01$ \\
\hline Nicotine substitution ${ }^{\dagger}, \mathrm{n}(\%)$ & $61(6.2)$ & $401(4.4)$ & 0.017 \\
\hline Use of any inhaled medication, $\mathrm{n}(\%)$ & $59(5.9)$ & $565(4.8)$ & 0.146 \\
\hline Passive smoking exposure (hours/day), median (IQR) & $7.0(0.0-20.0)$ & $6.0(0.0-20)$ & 0.831 \\
\hline Passive smoking in childhood (years), mean (SD) & $11.5(7.9)$ & $11.9(7.7)$ & 0.119 \\
\hline \multicolumn{4}{|l|}{ Other early-life and late-life exposures } \\
\hline Preterm delivery, $\mathrm{n}(\%)$ & $73(7.3)$ & $461(7.3)$ & 1.000 \\
\hline \multicolumn{4}{|l|}{ Educational level after high school } \\
\hline No education, $\mathrm{n}(\%)$ & $116(11.4)$ & $444(7.0)$ & $<0.0001$ \\
\hline Short (<3 years), $n(\%)$ & $102(10.0)$ & $481(7.5)$ & \\
\hline Vocational, n (\%) & $299(29.4)$ & $2193(34.4)$ & \\
\hline Middle length, $n(\%)$ & $230(22.6)$ & $1824(28.6)$ & \\
\hline University degree, $\mathrm{n}(\%)$ & $269(26.5)$ & $1431(22.5)$ & \\
\hline \multicolumn{4}{|l|}{ Pneumonia/acute bronchitis within the past 10 years ${ }^{\ddagger}, \mathrm{n}(\%)$} \\
\hline No & $669(67.4)$ & $4976(42.4)$ & $<0.0001$ \\
\hline $1-5$ times & $276(27.8)$ & 5566 (47.4) & \\
\hline $6-10$ times & $25(2.5)$ & $1117(9.5)$ & \\
\hline$>10$ times & $23(2.3)$ & $80(0.7)$ & \\
\hline
\end{tabular}

Cumulative smoking is defined as (average number of cigarettes per day/20) $\times$ number of years smoked).

Passive smoking during childhood was self-reported and reported in years (before 18 years of age). If percentages in each category do not add to $100 \%$, it is due to missing values for that variable.

*For current or former smokers.

†Nicotine substitution includes any type of gum, patch, inhaler or tablets with nicotine.

$\ddagger$ Pneumonia/bronchitis was defined as an episode requiring sick leave and/or consultation by medical doctor in the past 10 years.

BMI, body mass index; PLWHIV, people living with HIV.

\section{Prevalence estimates of airflow limitation}

Dynamic pulmonary function indices are depicted in table 3 . $\mathrm{FEV}_{1} /$ FVC $<$ LLN was equally common in PLWHIV of $10.6 \%(95 \%$ CI 8.9 to 12.6) and uninfected controls of $10.6 \%$ (95\% CI 10.1 to 11.1$), \mathrm{P}=1.0 . \mathrm{FEV}_{1} / \mathrm{FVC}<\mathrm{LLN}$ was found in $4.2 \%(2.5-6.8)$ and 6.6\% (6.0-7.3) in PLWHIV and controls who never smoked, respectively. In current and former smokers, the prevalence of $\mathrm{FEV}_{1} / \mathrm{FVC}<\mathrm{LLN}$ was $14.0 \%(11.5-16.8)$ and $12.5 \%$ (11.6-13.3), $\mathrm{P}=0.31$, respectively. A different prevalence estimate for airflow limitation was obtained when $\mathrm{FEV}_{1} / \mathrm{FVC}<0.7$ with $\mathrm{FEV}_{1}$ predicted $<80 \%$ were used as $10.0 \%(8.3-11.9)$ of PLWHIV and $5.8 \%$ (5.4-6.2) of controls, $\mathrm{P}<0.0001$, were found to have airflow limitation (table 3). In current and former smokers, the prevalence for this outcome was $13.1 \%(10.7-15.8)$ and $8.4 \%$ (7.7-9.1), $\mathrm{P}<0.0001$, respectively. Venn diagrams of the two outcomes are depicted in online supplementary figure S3. The prevalence of $\mathrm{FEV}_{1} / \mathrm{FVC}<0.7$ was $15.6 \%$ vs $17.8 \%, \mathrm{P}=0.08$. Severity grades of airflow limitation tended to be higher among PLWHIV (table 3).

\section{Z-scores of spirometric indices}

Histograms for $\mathrm{FEV}_{1}, \mathrm{FVC}$ and $\mathrm{FEV}_{1} / \mathrm{FVC} \mathrm{z}$-scores are depicted in figure 1. Mean (SD) $\mathrm{FEV}_{1}$ and FVC z-scores were lower for PLWHIV compared with controls $(-0.7$ (1.1) vs -0.1 (1.1), 


\begin{tabular}{|c|c|}
\hline & PLWHIV ( $n=1083)$ \\
\hline \multicolumn{2}{|l|}{ Mode of HIV transmission, $\mathrm{n}(\%)$} \\
\hline MSM & $771(71.8)$ \\
\hline Heterosexual & $225(20.9)$ \\
\hline IDU & $16(1.5)$ \\
\hline Other & $62(5.8)$ \\
\hline \multicolumn{2}{|l|}{ Current $\mathrm{CD} 4$ per $\mu \mathrm{L}, \mathrm{n}(\%)$} \\
\hline$<200$ & $19(1.8)$ \\
\hline 200-349 & $58(5.4)$ \\
\hline $350-500$ & $163(15.2)$ \\
\hline$>500$ & $832(77.6)$ \\
\hline CD4 nadir <200 per $\mu \mathrm{L}, \mathrm{n}(\%)$ & $442(41.8)$ \\
\hline CD4:CD8 ratio, median (IQR) & $0.8(0.6-1.1)$ \\
\hline Current cART use, $n(\%)$ & $1064(98.5)$ \\
\hline HIV RNA < 50 copies/mL, n (\%) & 1015 (94.6) \\
\hline Time with HIV, years & $14.5(9.0)$ \\
\hline Previous AIDS defining event, $\mathrm{n}(\%)$ & $190(17.5)$ \\
\hline Detectable HBsAg, n (\%) & $40(3.7)$ \\
\hline Detectable HCV RNA, n (\%) & $58(5.4)$ \\
\hline Previous PCP, $\mathrm{n}(\%)$ & $71(6.6)$ \\
\hline Previous TB, $\mathrm{n}(\%)$ & $21(1.9)$ \\
\hline
\end{tabular}

$\mathrm{P}<0.0001)$ and $(-0.5(1.0)$ vs $0.1(1.0), \mathrm{P}<0.0001)$. Mean $\mathrm{FEV}_{1} / \mathrm{FVC} \mathrm{z}$-scores were slightly lower for controls ( -0.4 (1.0) vs $-0.3(1.1), \mathrm{P}<0.0001)$.

\section{Risk factors associated with pulmonary function}

We performed univariate and multivariate logistic regression analyses to determine risk factors associated with $\mathrm{FEV}_{1} /$ FVC $<$ LLN (table 4). HIV was not associated with airflow limitation based on LLN in any of the two models (table 4). We also found no evidence for interaction of HIV with cumulative smoking on risk of airflow limitation $(\mathrm{P}=0.25)$, which shows that treated HIV does not modify the effect of smoking (online supplementary figure S4). HIV was independently associated with $\mathrm{FEV}_{1} / \mathrm{FVC}<0.7$ with $\mathrm{FEV}_{1}$ predicted $<80 \%$ in both models considered, that is, OR 1.71 (1.34-2.16, $\mathrm{P}<0.0001)$ (model 1: adjusted for age, sex, ancestry and cumulative smoking) and OR 1.40 (1.05-1.85, $\mathrm{P}=0.02$ ) (model 2: adjusted for age, sex, ancestry, cumulative smoking, educational level, previous pneumonia, preterm delivery and passive smoking during childhood). Similar results were obtained in analyses that were confined to spirometric procedures that were graded as easy (OR 1.03 (0.77$1.34, \mathrm{P}=0.85)$ for $\mathrm{LLN}$ and OR $1.79(1.32-2.39, \mathrm{P}<0.001)$ for $\mathrm{FEV}_{1} / \mathrm{FVC}<0.7$ with $\mathrm{FEV}_{1}$ predicted $<80 \%$ ) and when smoking was modelled as smoking status (current, former and never smoking) or categorised according to pack-years (0-10, 10-30 and >30 pack-years).

Using continuous outcome variables of absolute $\mathrm{FEV}_{1}$ and FVC in linear regressions models, HIV was associated with a $253 \mathrm{~mL}$ $(212-294, \mathrm{P}<0.0001)$ or $-6.8 \%(-7.8$ to $(-5.8), \mathrm{P}<0.0001)$ lower $\mathrm{FEV}_{1}$ in model 1 and $197 \mathrm{~mL}(152-242, \mathrm{P}<0.0001)$ or $-6.3 \%$ ( -7.4 to $(-5.1), \mathrm{P}<0.0001)$ lower $\mathrm{FEV}_{1}$ in model 2 (online supplementary table S1). HIV was also associated with a $395 \mathrm{~mL}(344-447, \mathrm{P}<0.0001)$ or $-8.2 \%(-9.2$ to $(-7.3)$, $\mathrm{P}<0.0001)$ lower FVC in model 1 and $328 \mathrm{~mL}(272-385$, $\mathrm{P}<0.0001)$ lower FVC or $-7.9 \%(-9.0$ to $(-6.9), \mathrm{P}<0.0001)$ in model 2. Similar results were obtained in analyses that were confined to high-graded spirometries, after including marijuana smoke as a covariate, and after excluding PLWH with a prior diagnosis of PCP or TB (data not shown).

\section{Self-reported morbidity}

Self-reported morbidity (mMRC, cough and sputum) and self-reported COPD, but not asthma, tended to be more common in PLWHIV, independent of smoking history (table 5). A total of 17.5\% (11.6-25.8) of PLWHIV with $\mathrm{FEV}_{1} / \mathrm{FVC}<\mathrm{LLN}$ reported a previous diagnosis of COPD, whereas only $12.8 \%$ (10.4-15.6) of controls with airflow limitation based on LLN reported COPD. Moreover, 21.0\% (14.3-29.7) of PLWHIV and 15.2\% (13.2-17.4) of controls with $\mathrm{FEV}_{1} / \mathrm{FVC}<\mathrm{LLN}$ reported use of any inhaled medication.

\section{HIV-associated factors and pulmonary function}

Considering PLWHIV separately, most recent CD4+ Tcell count, CD4 + Tcell nadir, CD4/CD8 ratio, detectable viral replication ( $>50$ copies $/ \mathrm{mL}$ ), previous AIDS defining condition, previous PCP and time living with HIV were not associated with

Table 3 Dynamic pulmonary function in PLWHIV and uninfected controls stratified by smoking status

\begin{tabular}{|c|c|c|c|c|c|c|}
\hline & PLWHIV (n=1083) & Controls $(n=12074)$ & P value* & $\begin{array}{l}\text { Never smoking } \\
\text { PLWHIV }(n=360)\end{array}$ & $\begin{array}{l}\text { Never smoking } \\
\text { controls }(n=5717)\end{array}$ & $P$ valuet \\
\hline $\mathrm{FEV}_{1} / \mathrm{FVC}<\mathrm{LLN}, \mathrm{n}(\%)$ & $114(10.6)$ & $1278(10.6)$ & 1.0 & $15(4.2)$ & $378(6.6)$ & 0.09 \\
\hline $\mathrm{FEV}_{1} \geq 80 \%$ predicted & $29(25.4)$ & $747(58.5)$ & - & $6(40.0)$ & $246(65.1)$ & - \\
\hline FEV, $50 \%-79 \%$ predicted & $69(60.5)$ & $463(36.2)$ & - & $8(53.3)$ & $128(33.9)$ & - \\
\hline FEV, $30 \%-49 \%$ predicted & $13(11.4)$ & $63(4.9)$ & - & $1(6.7)$ & $3(0.8)$ & - \\
\hline $\mathrm{FEV}_{1}<30 \%$ predicted & $3(2.6)$ & $5(0.4)$ & - & $0(0.0)$ & $1(0.3)$ & - \\
\hline $\mathrm{FEV}_{1} / \mathrm{FVC}<0.7$ and $\mathrm{FEV}_{1}$ predicted $<80 \%$ & $108(10.0)$ & $696(5.8)$ & $<0.001$ & $14(3.9)$ & $177(3.1)$ & 0.50 \\
\hline FEV, $50 \%-79 \%$ predicted & $92(85.1)$ & $625(89.8)$ & - & $13(92.9)$ & $172(97.2)$ & - \\
\hline FEV $30 \%-49 \%$ predicted & $13(12.0)$ & $66(9.5)$ & - & $1(7.1)$ & $4(2.2)$ & - \\
\hline $\mathrm{FEV}_{1}<30 \%$ predicted & $3(2.8)$ & $5(0.7)$ & - & $0(0.0)$ & $1(0.6)$ & - \\
\hline
\end{tabular}

${ }^{*}$ Comparing PLWHIV with controls.

†Comparing never smoking PLWHIV with never smoking controls.

LLN, lower limit of normal; PLWHIV, people living with HIV. 
A

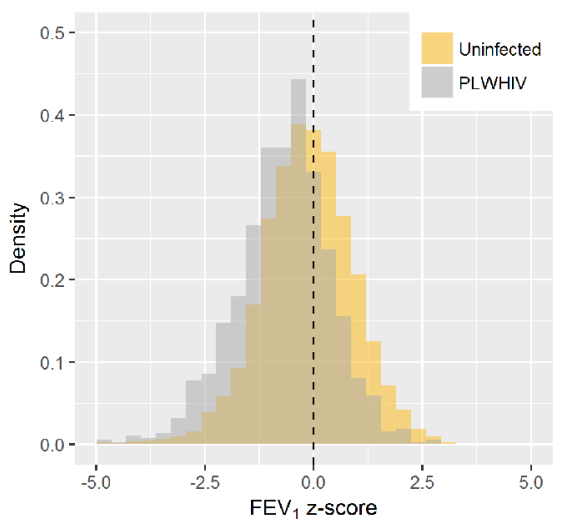

B

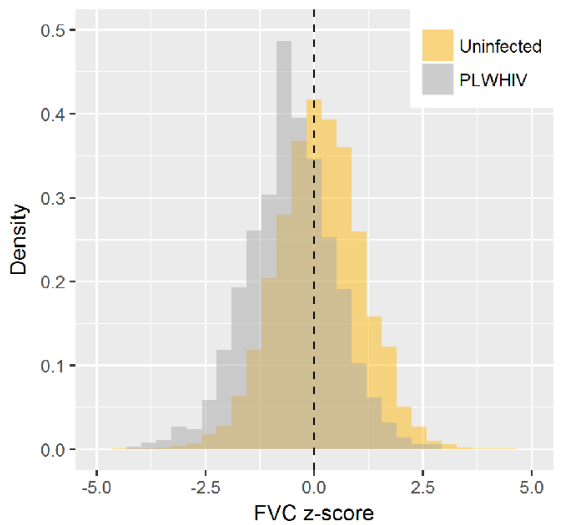

c

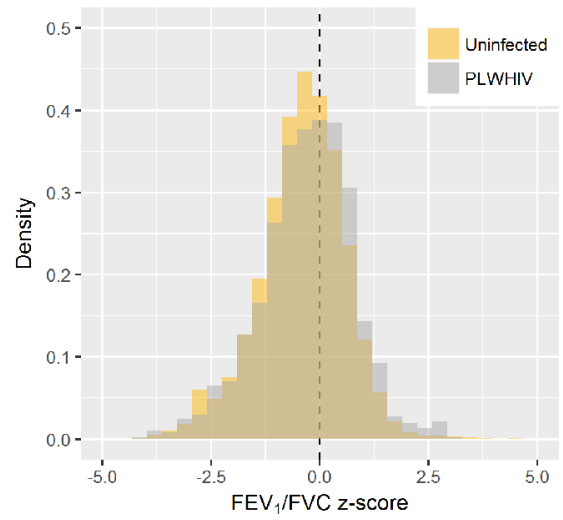

Figure 1 Histograms of (A) FEV $1^{\prime}$ (B) FVC and (C) FEV /FVC z-scores for people living with HIV (PLWHIV) and uninfected controls. Z-scores are interpreted independent of age, sex and ethnic group. Z-scores were derived from equations provided by the Global Lung Function Initiative.

airflow limitation (LLN). Of these variables, only CD4+ T cell nadir was significantly associated with lower $\mathrm{FEV}_{1}$ and FVC after adjusting for age, sex, ancestry and cumulative smoking. Thus, a 100 cells $/ \mathrm{mm}^{3}$ lower CD4 + T cell nadir was associated with a $30 \mathrm{~mL}(7-52, \mathrm{P}<0.01)$ lower $\mathrm{FEV}_{1}$ and $51 \mathrm{~mL}(24-78$, $\mathrm{P}<0.001)$ lower FVC.

\section{DISCUSSION}

The epidemiological landscape of respiratory disease in HIV has changed, and studies are needed to ascertain the long-term respiratory health consequences of HIV. To our knowledge, this study represents the largest analysis of pulmonary function in PLWHIV and uninfected controls. We found a similar prevalence of $\mathrm{FEV}_{1} / \mathrm{FVC}$ below LLN in PLWHIV compared with age-matched and sex-matched uninfected controls. However, HIV was independently associated with approximately 200 and $350 \mathrm{~mL}$ lower $\mathrm{FEV}_{1}$ and $\mathrm{FVC}$, respectively, which seems to be associated with prior immune deficiency. These findings suggest that HIV-specific disease mechanisms contribute to lower dynamic pulmonary function.

Table 4 Prediction of airflow limitation (LLN) by multivariate regression analyses

\begin{tabular}{|c|c|c|c|}
\hline & Crude OR $(95 \% \mathrm{Cl})$ & Model 1 OR $(95 \% \mathrm{Cl})$ & Model 2 OR $(95 \% \mathrm{Cl})$ \\
\hline HIV, yes versus no & $1.00(0.81$ to 1.22$)$ & 0.97 (0.77 to 1.21$)$ & $0.86(0.66$ to 1.11$)$ \\
\hline Age, per decade ${ }^{*}$ & $0.89(0.85$ to 0.94$)$ & $0.97(0.92$ to 1.03$)$ & $1.03(0.95$ to 1.11$)$ \\
\hline Sex, male versus female ${ }^{*}$ & $1.03(0.89$ to 1.19$)$ & $0.81(0.69$ to 0.94$)$ & $0.89(0.72$ to 1.12$)$ \\
\hline \multicolumn{4}{|l|}{ Ancestry } \\
\hline Scandinavian & Ref & Ref & Ref \\
\hline Other European & $0.87(0.69$ to 1.10$)$ & $0.92(0.72$ to 1.15$)$ & 0.92 (0.66 to 1.27$)$ \\
\hline Middle East/Indian subcontinent & 1.07 (0.77 to 1.46$)$ & $1.15(0.81$ to 1.58$)$ & - \\
\hline Other & $0.95(0.60$ to 1.43$)$ & 1.07 (0.65 to 1.69$)$ & $0.88(0.41$ to 1.65$)$ \\
\hline Pack-years of smoking, per 10 pack-years & $1.32(1.29$ to 1.37$)$ & 1.35 (1.31 to 1.39$)$ & $1.33(1.27$ to 1.39$)$ \\
\hline Passive smoking during childhood, per 5 years & $1.12(1.06$ to 1.17$)$ & & $1.04(0.98$ to 1.10$)$ \\
\hline Prematurity, yes versus no & 1.29 (0.98 to 1.68$)$ & & 1.43 (1.07 to 1.89$)$ \\
\hline \multicolumn{4}{|l|}{ Educational level } \\
\hline No education & Ref & - & Ref \\
\hline Short (<3years) & 0.77 (0.54 to 1.10$)$ & - & $0.95(0.65$ to 1.41$)$ \\
\hline Vocational & $0.81(0.62$ to 1.07$)$ & - & $0.94(0.70$ to 1.28$)$ \\
\hline Middle length & $0.60(0.46$ to 0.80$)$ & - & 0.79 (0.58 to 1.09$)$ \\
\hline University degree & 0.54 (0.40 to 0.73$)$ & - & $0.88(0.63$ to 1.24$)$ \\
\hline \multicolumn{4}{|c|}{ Pneumonia/acute bronchitis within the past 10 years ${ }^{\dagger}, \mathrm{n}(\%)$} \\
\hline None & Ref & - & Ref \\
\hline $1-5$ times & $1.10(0.97$ to 1.25$)$ & - & $1.41(1.17$ to 1.70$)$ \\
\hline $6-10$ times & 1.64 (1.35 to 1.98$)$ & - & $3.01(1.75$ to 5.02$)$ \\
\hline$>10$ times & 3.68 (2.31 to 5.69$)$ & - & $4.68(2.29$ to 9.21$)$ \\
\hline
\end{tabular}

${ }^{*}$ Age and sex were matching variables and effect sizes cannot be interpreted. Model 1 was adjusted for age, sex, ancestry, cumulative smoking (pack-years) and HIV status. Model 2 was adjusted for the same variables, as well as preterm delivery, passive smoking during childhood, educational status and pneumonia within the past 10 years. †Pneumonia/bronchitis was defined as an episode requiring sick leave and/or consultation by medical doctor in the past 10 years. LLN, lower limit of normal. 
Table 5 Self-reported respiratory morbidity and biochemical markers

\begin{tabular}{|c|c|c|c|c|c|c|}
\hline & PLWHIV ( $n=1083)$ & Controls $(n=12$ 074) & $P$ value & $\begin{array}{l}\text { Never smoking } \\
\text { PLWHIV }(n=361)\end{array}$ & $\begin{array}{l}\text { Never smoking } \\
\text { controls }(n=5726)\end{array}$ & $P$ value \\
\hline \multicolumn{7}{|l|}{ mMRC, n (\%) } \\
\hline 0 & $696(68.2)$ & $9235(77.7)$ & $<0.0001$ & $265(75.9)$ & $4769(83.5)$ & $<0.01$ \\
\hline 1 & $245(24.5)$ & $2167(18.2)$ & & $70(20.1)$ & $818(14.3)$ & \\
\hline 2 & $49(4.8)$ & $288(2.4)$ & & $8(2.3)$ & $82(1.4)$ & \\
\hline 3 & $18(1.8)$ & $126(1.1)$ & & $3(0.9)$ & $31(0.5)$ & \\
\hline 4 & $12(1.2)$ & $66(0.6)$ & & $3(0.9)$ & $11(0.2)$ & \\
\hline Cough, n (\%) & $131(12.9)$ & $807(6.8)$ & $<0.0001$ & $31(8.9)$ & $230(4.0)$ & $<0.0001$ \\
\hline Wheezing, $\mathrm{n}(\%)$ & $226(22.0)$ & $1882(15.8)$ & $<0.0001$ & $39(11.1)$ & $638(11.2)$ & 1.000 \\
\hline Sputum, n (\%) & $178(17.5)$ & $597(9.4)$ & $<0.0001$ & $40(11.5)$ & $169(5.5)$ & $<0.0001$ \\
\hline Gastro-oesophageal reflux, n (\%) & $228(22.1)$ & $1054(16.5)$ & $<0.0001$ & $64(18.1)$ & $417(13.6)$ & 0.026 \\
\hline Self-reported asthma, n (\%) & $64(6.4)$ & $711(6.0)$ & 0.693 & $15(4.4)$ & $375(6.6)$ & 0.125 \\
\hline Self-reported COPD, n (\%) & $32(3.1)$ & $127(2.0)$ & 0.030 & $1(0.3)$ & $8(0.3)$ & 1.000 \\
\hline WBC $\left(\times 10^{9} / L\right)$, mean $(S D)$ & $6.8(1.8)$ & $7.1(2.9)$ & 0.017 & $6.4(1.6)$ & $6.7(2.9)$ & 0.035 \\
\hline Eosinophils $\left(\times 10^{9} / \mathrm{L}\right)$, mean $(\mathrm{SD})$ & $0.2(0.1)$ & $0.2(0.1)$ & 0.030 & $0.2(0.1)$ & $0.2(0.1)$ & 0.154 \\
\hline Fibrinogen $(\mu \mathrm{mol} / \mathrm{L})$, mean $(\mathrm{SD})$ & $9.6(2.3)$ & $10.1(2.0)$ & $<0.0001$ & $9.2(2.1)$ & $9.9(1.9)$ & $<0.0001$ \\
\hline hsCRP (mg/L), mean (SD) & $2.8(7.1)$ & $1.9(5.0)$ & $<0.0001$ & $2.1(3.6)$ & $1.7(3.4)$ & 0.037 \\
\hline
\end{tabular}

If frequencies do not correspond to absolute numbers it is due to missing variables.

hsCRP, high-sensitivity C-reactive protein; mMRC, modified British Medical Research Council breathlessness scale; PLWHIV, people living with HIV; WBC, white blood cells.

Several factors influence COPD development and progression. Although cigarette smoking is the most well-studied risk factor, individuals who never smoke may develop chronic airflow limitation. In fact, approximately half of patients with moderate to severe COPD have developed the disease due to abnormal lung growth and development rather than due to an accelerated lung function decline during adult life. ${ }^{18}$ More concrete issues such as equipment use, seasonal and circadian variation may also affect results of spirometry. ${ }^{24}$ For this reason, strictly uniformly collected epidemiological and physiological data were prioritised in this study, and enabled us to explore the independent effect of HIV infection on pulmonary function.

The Veterans Aging Cohort study from the current cART era found HIV to be an independent risk factor for COPD using International Classification of Diseases, Ninth Revision, diagnosis codes and self-reports. ${ }^{2526}$ However, these studies relied on diagnostic codes without spirometry evidence and lacked information on confounders associated with lung function decline, or were not able to adjust for cumulative smoking, ${ }^{25}$ which may be a better predictor of COPD than smoking categorisation. ${ }^{27}$ Spirometric studies may draw a more precise estimate of COPD and be more suitable for evaluating the pulmonary effects of HIV. Several smaller studies have assessed pulmonary function in PLWHIV (online supplementary figure S1). The four largest spirometric studies include the Strategic Timing of Antiretroviral Treatment (START) pulmonary substudy $(n=1026),{ }^{28}$ the Lung-HIV consortium study $(\mathrm{n}=908),{ }^{9}$ the France REcherche Nord \& Sud Sida-HIV et He'patites (ANRS) EP48 HIV-CHEST cohort of smokers with prior immune deficiency (CD4 nadir count $<350$ cells $\left./ \mathrm{mm}^{3}\right)$ above 40 years of age $(n=351)^{19}$ and the AIDS Linked to the IntraVenous Experience (ALIVE) study of injection drug users ( $n=303$ PLWHIV). ${ }^{29}$ The latter two studies also included uninfected controls and were able to evaluate the effect of HIV. Although HIV status itself was not found to be a risk factor for $\mathrm{FEV}_{1} / \mathrm{FVC}<\mathrm{LLN}$ in the ALIVE study, poorly controlled HIV (viral load $\geq 200000$ copies $/ \mathrm{mL}$ ) was associated with higher odds of airflow limitation. ${ }^{29}$ Due to the very limited number of individuals with ongoing viral replication in our study, we were not able to evaluate the effect of very high levels of viraemia, and viral loads above 50 copies $/ \mathrm{mL}$ were not associated with any of our outcomes. The ANRS EP48 study did not assess the LLN but found HIV to be independently associated with $\mathrm{FEV}_{1} / \mathrm{FVC}<0.7$ with $\mathrm{FEV}_{1}$ predicted $<80 \%$ (OR 1.72), which was similar to our results.

Our prevalence estimate of airflow limitation in PLWHIV $(10.6 \%)$ is comparable to earlier reports, ${ }^{30-32}$ but several studies have found estimates exceeding $15 \%$. $^{4-9}$ These variations may be explained by uneven distribution of conventional risk factors, primarily age and tobacco smoking, and the use of different criteria for airflow limitation. The variations may also capture uneven distribution of other non-HIV and HIV-related risk factors. Such risk factors may deserve attention as they can be affected by preventive measures. In our primary analyses, educational status and pneumonia seemed to be important (doseresponse dependent) predictors of both airflow limitation (LLN) and lower absolute FEV 1 and FVC. None of the HIV variables studied, however, seemed to predict $\mathrm{FEV}_{1} / \mathrm{FVC}<\mathrm{LLN}$, but a low CD4 nadir was associated with lower $\mathrm{FEV}_{1}$ and FVC. These findings coincide with the START pulmonary substudy. This study included PLWHIV with initial CD4 cell counts $>500$ cells/ $\mu \mathrm{L}$ and randomised participants to either immediate or deferred cART. However, the average CD4 count in the deferred arm was $>600$ cells per $\mu \mathrm{L}$ during follow-up. Thus, the timing of cART had no effect on the rate of lung function decline when CD4 cell counts were high, which may be in line with the notion that immune deficiency associated with HIV, rather than HIV per se, is a driver for loss of pulmonary function.

Individuals who refrain from smoking may provide additional insight into HIV disease mechanisms. We previously found evidence in well-treated PLWHIV who never smoked of small airway abnormalities, as evaluated by multiple breath washouts of nitrogen, despite having normal spirometric indices. ${ }^{14}$ In the present study, 4\% of individuals who never smoked had $\mathrm{FEV}_{1} /$ FVC $<$ LLN. Notably, in the multicontinental START study, 
where participants were screened for good health and had a low median age at 36 , half of those with $\mathrm{FEV}_{1} / \mathrm{FVC}<\mathrm{LLN}$ were found to be never smokers. ${ }^{28}$ This observation may be explained by exposure to biomass fuel exposure, and respiratory tract infections during childhood, which are important risk factors in developing countries. ${ }^{33}$ Although these risk factors also seem to be important in our setting (13\% of PLWHIV with airflow limitation never smoked), they may have greater significance in low-resource settings.

We were unable to determine why PLWHIV have a similar prevalence of $\mathrm{FEV}_{1} / \mathrm{FVC}<\mathrm{LLN}$ (our primary outcome) as uninfected controls but a higher prevalence of $\mathrm{FEV}_{1} / \mathrm{FVC}<0.7$ with $\mathrm{FEV}_{1}$ predicted $<80 \%$. Estimates of airflow limitation for PLWHIV based on the two criteria were very similar $(10.6 \%$ vs $10.0 \%$ ) whereas they seemed to differ more substantially in uninfected controls $(10.0 \%$ vs $5.8 \%)$. A larger number of uninfected controls meet LLN criteria while having $\mathrm{FEV}_{1}>80 \%$ predicted $(58.5 \%)$ which was less frequently occurring in PLWHIV (25.4\%). Thus, differences in severity of airflow limitation between the two cohorts may explain the discrepancy using the two outcome measures. Moreover, PLWHIV did not have a higher prevalence of $\mathrm{FEV}_{1} / \mathrm{FVC}<0.7$. The age discrepancy in the two cohorts may also have accounted for some of the difference although the discrepancy was still evident when analyses were confined to individuals above the age of $50(13.6 \%$ vs $10.3 \%$ with $\mathrm{FEV}_{1} / \mathrm{FVC}<\mathrm{LLN}$ and $14.8 \%$ vs $7.9 \%$ with $\mathrm{FEV}_{1} / \mathrm{FVC}<0.7$ with $\mathrm{FEV}_{1}$ predicted $<80 \%$, respectively). Finally, the discrepancy in ethnicity did not affect the results and restricting analyses to Scandinavians yielded similar estimates $(11.2 \%$ vs $10.7 \%$ with $\mathrm{FEV}_{1} / \mathrm{FVC}<\mathrm{LLN}$ and $10.5 \%$ vs $5.9 \%$ with $\mathrm{FEV}_{1} / \mathrm{FVC}<0.7$ with $\mathrm{FEV}_{1}$ predicted $<80 \%$ for PLWHIV and uninfected controls, respectively).

A large proportion of PLWHIV (82\%) and controls (87\%) with $\mathrm{FEV}_{1} / \mathrm{FVC}<\mathrm{LLN}$ had no self-reported COPD, suggesting that COPD is grossly underdiagnosed in both cohorts. Screening of COPD in PLWHIV, however, cannot be recommended based on these findings, and there are currently no data indicating that such an approach would lead to improved outcomes. We also found no evidence of disparity in inhaled therapies or pharmacological treatment of tobacco dependence for PLWHIV. A total of $21 \%$ and $15 \%$ of PLWHIV and controls with $\mathrm{FEV}_{1} / \mathrm{FVC}<\mathrm{LLN}$ were receiving some kind of inhaled therapy, respectively, and $9 \%$ current smokers with HIV received nicotine replacement therapy compared with $8 \%$ for uninfected controls.

Few mechanistic studies have assessed the respiratory effects of well-treated HIV and most studies are limited by cross-sectional designs. Initiation of cART reduces viral load in the lung compartment, ${ }^{34}$ but some replication in the lungs may still occur despite systemic suppression. ${ }^{35}$ This may, theoretically, cause direct or indirect lung damage, impair immune functions and render the host susceptible to noxious stimuli. Although we did not find interaction between smoking and treated HIV, one small study found depletion of lung mucosal CD4+ Tcells, deficient functional responses of these cells, as well as increased expression of proapoptotic markers, in PLWHIV with COPD compared with uninfected individuals with COPD. ${ }^{36}$ Other evidence suggests that altered lung microbiome may be a contributor to COPD pathogenesis. P. jirovecii colonisation has received attention as it was found to be associated with airflow limitation. ${ }^{37}$ However, we were not able to confirm this association, ${ }^{38}$ and another recent study has shown that microbial populations in the lungs of well-treated PLWHIV did not differ from uninfected individuals. ${ }^{39}$
Our study has limitations. First, spirometry is effort dependent and PLWHIV may perform worse, although our findings were similar in analysis confined to spirometries where instructions were graded as easy. Second, although HIV was associated with decreased FVC (a feature of both restrictive and obstructive ventilator defects), we did not confirm a restrictive ventilatory defect by body plethysmography, which would be essential for determination of total lung capacity. ${ }^{40}$ Chest CT would also have provided further insight into the underlying pathology. Third, several covariates, including previous episodes of pneumonia, were based on self-reports and recall bias cannot be precluded. Fourth, the COCOMO cohort comprised predominantly white men that may have a lower burden of respiratory risk factors compared with other cohorts, and our findings may not be generalisable to PLWHIV in other parts of the world. Fifth, our results may be subjected to unmeasured residual confounding, although we tried to adjust for several early-life and late-life risk factors in multivariate analyses. Finally, the two cohorts may be subjected to selection bias such as healthy volunteer bias, as CGPS participants were recruited by postal mail (response rate $\approx 45 \%$ ), whereas COCOMO participants were recruited at ambulatory visits (response rate $\approx 42 \%$ ).

In summary, in a well-treated cohort of PLWHIV, HIV was not associated with $\mathrm{FEV}_{1} / \mathrm{FVC}<\mathrm{LLN}$ but rather seemed to be a driver for concurrently decreased FEV and FVC. Although tobacco smoking cessation should be a priority in any individual, it may have even greater priority in the care of PLWHIV. Cohort studies exploring longitudinal change in spirometry, other measures of lung function and CT imaging in PLWHIV and uninfected controls are needed to better characterise lung abnormalities and elucidate their causes. Moreover, these findings have to be related to symptoms in PLWHIV in different geographical settings who have acquired HIV infection via different routes of transmission.

Acknowledgements We thank all the study subjects for their participation. We thank the staff at the Department of Infectious Diseases at Rigshospitalet and at Hvidovre Hospital for their dedicated participation.

Contributors AnR was responsible for concept, data collection, and statistical analysis, and drafted the manuscript. JL, TB, JG, BGN and JV were responsible for concept and have had content review and editing input. SA was partly responsible for statistical analysis and has had content review and editing input. AR and AM had content review and editing input, and provided statistical support. SDN was the project leader, was responsible for concept and data collection, and has had content review and editing input.

Funding This work was supported by Rigshospitalet Research Council, Region Hovedstaden, the Lundbeck Foundation, the Novo Nordisk Foundation, and the Danish National Research Foundation grant 126. The study was designed, conducted, analysed and written by the authors without involvement of any commercial party.

Competing interests AnR: Travelling grants from Gilead. TB: Personal fees from Bristol Myers Squibb (BMS) and from Gilead and non-financial support from BMS, and from Gilead. AsR: No conflicts of interests. AM: Honoraria, lecture fees and travel support from BMS, BI, Pfizer, Merck, ViiV and Wragge. JG: Honoraria for consulting and presenting paid to his institution from Gilead, Abbvie, ViiV, BMS, MSD, Janssen and Medivir. JV: Honoraria for consulting and presenting from AstraZeneca, Boehringer-Ingelheim, Chiesi, GlaskoSmithKline and Novartis. SDN: Unrestricted research grants from the Novo Nordisk Foundation, the Lundbeck Foundation and the Rigshospitalet Research Council; travelling grants from Gilead, MSD, BMS and GSK/ViiV; advisory board activity for Gilead and GSK/ViiV.

Ethics approval The study was approved by the Regional Ethics Committee of Copenhagen (COCOMO: H-15017350; CGPS: H-KF-01-144/01). Written informed consent was obtained from all participants.

Provenance and peer review Not commissioned; externally peer reviewed.

(C) Article author(s) (or their employer(s) unless otherwise stated in the text of the article) 2018. All rights reserved. No commercial use is permitted unless otherwise expressly granted. 


\section{REFERENCES}

1 Ryom L, Boesecke C, Gisler V, et al. Essentials from the 2015 European AIDS Clinical Society (EACS) guidelines for the treatment of adult HIV-positive persons. HIV Med 2016;17:83-8.

2 GBD 2015 Mortality and Causes of Death Collaborators. Global, regional, and national life expectancy, all-cause mortality, and cause-specific mortality for 249 causes of death, 1980-2015: a systematic analysis for the Global Burden of Disease Study 2015. Lancet 2016;388:1459-544.

3 Vogelmeier CF, Criner GJ, Martinez FJ, et al. Global strategy for the diagnosis, management, and prevention of chronic obstructive lung disease 2017 report: GOLD executive summary. Eur Respir J 2017;49:1700214.

4 Drummond MB, Merlo CA, Astemborski J, et al. The effect of HIV infection on longitudinal lung function decline among IDUs: a prospective cohort. AIDS 2013;27:1303-11.

5 Gingo MR, George MP, Kessinger CJ, et al. Pulmonary function abnormalities in HIVinfected patients during the current antiretroviral therapy era. Am J Respir Crit Care Med 2010;182:790-6.

6 Sampériz G, Guerrero D, López M, et al. Prevalence of and risk factors for pulmonary abnormalities in HIV-infected patients treated with antiretroviral therapy. HIV Med 2014;15:321-9.

7 Madeddu G, Fois AG, Calia GM, et al. Chronic obstructive pulmonary disease: an emerging comorbidity in HIV-infected patients in the HAART era? Infection 2013:41:347-53.

8 Makinson A, Hayot M, Eymard-Duvernay $S$, et al. High prevalence of undiagnosed COPD in a cohort of HIV-infected smokers. Eur Respir J 2015;45:828-31.

9 Drummond MB, Huang L, Diaz PT, et al. Factors associated with abnormal spirometry among HIV-infected individuals. AIDS 2015;29:1691-700.

10 Collini P, Morris A. Maintaining lung health with longstanding HIV. Curr Opin Infect Dis 2016;29:31-8.

11 Crothers K, McGinnis K, Kleerup E, et al. HIV infection is associated with reduced pulmonary diffusing capacity. J Acquir Immune Defic Syndr 2013;64:271-8.

12 Pefura-Yone EW, Fodjeu G, Kengne AP, et al. Prevalence and determinants of chronic obstructive pulmonary disease in HIV infected patients in an African country with low level of tobacco smoking. Respir Med 2015;109:247-54.

13 Attia EF, Akgün KM, Wongtrakool C, et al. Increased risk of radiographic emphysema in HIV is associated with elevated soluble CD14 and nadir CD4. Chest 2014; 146:1543-53.

14 Ronit A, Mathiesen IH, Gelpi M, et al. Small airway dysfunction in well-treated neversmoking HIV-infected individuals. Eur Respir J 2017:49:1602186.

15 Ronit A, Haissman J, Kirkegaard-Klitbo DM, et al. Copenhagen comorbidity in HIV infection (COCOMO) study: a study protocol for a longitudinal, non-interventional assessment of non-AIDS comorbidity in HIV infection in Denmark. BMC Infect Dis 2016:16:713.

16 Quanjer PH, Stanojevic S, Cole TJ, et al. Multi-ethnic reference values for spirometry for the 3-95-yr age range: the global lung function 2012 equations. Eur Respir J 2012;40:1324-43.

17 Thomsen $\mathrm{M}$, Ingebrigtsen TS, Marott JL, et al. Inflammatory biomarkers and exacerbations in chronic obstructive pulmonary disease. JAMA 2013;309:2353-61.

18 Lange $P$, Celli B, Agustí A, et al. Lung-function trajectories leading to chronic obstructive pulmonary disease. N Engl J Med 2015:373:111-22.

19 Makinson A, Hayot M, Eymard-Duvernay S, et al. HIV is associated with airway obstruction: a matched controlled study. AIDS 2018;32:227-232.

20 Barker DJ, Godfrey KM, Fall C, et al. Relation of birth weight and childhood respiratory infection to adult lung function and death from chronic obstructive airways disease. BMJ 1991;303:671-5.
21 Yin $\mathrm{P}$, Jiang CQ, Cheng KK, et al. Passive smoking exposure and risk of COPD among adults in China: the Guangzhou Biobank Cohort Study. Lancet 2007;370:751-7.

22 Prescott E, Vestbo J. Socioeconomic status and chronic obstructive pulmonary disease. Thorax 1999:54:737-41.

23 Donaldson GC, Seemungal TA, Bhowmik A, et al. Relationship between exacerbation frequency and lung function decline in chronic obstructive pulmonary disease. Thorax 2002; $57: 847-52$

24 Borsboom GJ, van Pelt W, van Houwelingen $\mathrm{HC}$, et al. Diurnal variation in lung function in subgroups from two Dutch populations: consequences for longitudinal analysis. Am J Respir Crit Care Med 1999;159:1163-71.

25 Crothers K, Huang L, Goulet JL, et al. HIV infection and risk for incident pulmonary diseases in the combination antiretroviral therapy era. Am J Respir Crit Care Med 2011;183:388-95.

26 Crothers K, Butt AA, Gibert CL, et al. Increased COPD among HIV-positive compared to HIV-negative veterans. Chest 2006;130:1326-33.

27 Guaraldi G, Raggi P, Gomes A, et al. Lung and heart diseases are better predicted by pack-years than by smoking status or duration of smoking cessation in HIV patients. PLoS One 2015;10:e0143700.

28 Kunisaki KM, Niewoehner DE, Collins G, et al. Pulmonary function in an international sample of HIV-positive, treatment-naïve adults with CD4 counts $>500$ cells $/ \mu \mathrm{L}$ : a substudy of the INSIGHT Strategic Timing of AntiRetroviral Treatment (START) trial. HIV Med 2015;16(Suppl 1):119-28.

29 Drummond MB, Kirk GD, Astemborski J, et al. Association between obstructive lung disease and markers of HIV infection in a high-risk cohort. Thorax 2012;67:309-14.

30 Risso K, Guillouet-de-Salvador F, Valerio L, et al. COPD in HIV-Infected Patients: CD4 Cell Count Highly Correlated. PLoS One 2017;12:e0169359.

31 Nakamura $\mathrm{H}$, Tateyama $\mathrm{M}$, Tasato $\mathrm{D}$, et al. The prevalence of airway obstruction among Japanese HIV-positive male patients compared with general population; a case-control study of single center analysis. J Infect Chemother 2014;20:361-4.

32 Brown J, McGowan JA, Chouial H, et al. Respiratory health status is impaired in UK HIV-positive adults with virologically suppressed HIV infection. HIV Med 2017;18:604-12.

33 Salvi SS, Barnes PJ. Chronic obstructive pulmonary disease in non-smokers. Lancet 2009;374:733-43.

34 Twigg lii $\mathrm{HL}$, Weiden $\mathrm{M}$, Valentine $\mathrm{F}$, et al. Effect of highly active antiretrovira therapy on viral burden in the lungs of HIV-infected subjects. J Infect Dis 2008;197:109-16

35 Cribbs SK, Lennox J, Caliendo AM, et al. Healthy HIV-1-infected individuals on highly active antiretroviral therapy harbor HIV-1 in their alveolar macrophages. AIDS Res Hum Retroviruses 2015:31:64-70.

36 Popescu I, Drummond MB, Gama L, et al. Activation-induced cell death drives profound lung CD4(+) T-cell depletion in HIV-associated chronic obstructive pulmonary disease. Am J Respir Crit Care Med 2014;190:744-55.

37 Morris A, Alexander T, Radhi S, et al. Airway obstruction is increased in pneumocystiscolonized human immunodeficiency virus-infected outpatients. J Clin Microbiol 2009;47:3773-6.

38 Ronit A, Klitbo DM, Kildemoes AO, et al. Absence of pneumocystis jirovecii colonization in human immunodeficiency virus-infected individuals with and without airway obstruction and with undetectable viral load. Open Forum Infect Dis 2016;3:ofw044.

39 Beck JM, Schloss PD, Venkataraman A, et al. Multicenter comparison of lung and oral microbiomes of HIV-infected and HIV-uninfected individuals. Am J Respir Crit Care Med 2015;192:1335-44.

40 Crapo RO. Pulmonary-function testing. N Engl J Med 1994;331:25-30. 